\title{
Use of mobile devices in medical education
}

DOI: $10.46932 / \operatorname{sfjdv2n2-008}$

Received in: November 1st, 2020

Accepted in: December 30th, 2020

\section{Raquel Morales}

Department of Legal and Forensic Medicine, Biomedical Research Institute (IMIB), Regional Campus of International Excellence "Campus Mare Nostrum", Faculty of Medicine, University of Murcia, (Murcia), Spain.

\section{Dr. Isabel Legaz Pérez}

Department of Sociosanitary Sciences. Area of Legal and Forensic Medicine, University of Murcia. Campus de Espinardo. E-30100. Murcia. Espinardo,

E-mail: isalegaz@um.es

\begin{abstract}
Background: The evaluation in real-time allows the teacher to improve the deficiencies and propose immediate improvement actions that allow the student's correct acquisition of knowledge.

Purpose: The objective was to implement in university students conduct real-time theoretical questionnaires in the classroom using mobile devices with real-time resolution and a later critical analysis of the results to improve the evaluation and learning process.

Sample: A total of 300 university students belonging to a Medicine degree were analyzed in this study. All students have participated in this study voluntarily.

Design and methods: A real-time questionnaire about Legal Medicine was conducted in the classroom using an online platform ("Live Interactive Audience Participation | Poll Everywhere" 2019). The students responded using Twitter. The students' different answers to the questionnaire's questions are visualized in real-time in the teaching classroom. A questionnaire with 13 items was developed to assess the students' opinions regarding this evaluation tool's use and capabilities.

Results: Our results show that $86.5 \%$ of students considered and were very useful in using this teaching resource, which increased students' interest in the subject taught (75.3\%). The use of real-time questionnaires in class showed a high degree of acceptance $(77.4 \%)$ in the group of delighted students and only $37 \%$ in the group of students not very satisfied with the experience ( $\mathrm{P}<0.001)$. A $43.8 \%$ of the student considered that the use of digital evaluation should increase in the classroom.

Conclusions: This digital evaluation tool is an appropriate didactic resource to develop in the classroom since it increases student motivation and promotes the students' natural and active participation.
\end{abstract}

Keywords: Digital evaluation, High education, Legal Medicine, Medicine students, Mobile learning, Science education,

\section{INTRODUCTION}

The rapid evolution of new digital technologies and the Internet are impacted in all the scientific community activities (Linn 2003), influencing the teaching and learning of all the thematic areas of science (Lee and Tsai 2013; Lee et al. 2011) outstandingly. Higher education has been evolving towards the incorporation of new alternative evaluation systems to traditional evaluation, all because there are 
more and more teacher initiatives that seek to explore new contexts for teaching and learning that are much more adapted to the requirements of higher education to the information society (Wu, Lu and Chang 2017; Alonso 2019; Gómez -Aguilar, Roses-Campos and Farias-Batlle 2012).

New technologies, specifically mobile devices, are revolutionizing the teaching and learning of science (Mackay, Anderson, and Harding 2017). Several studies show that mobile learning provides benefits for the student since it allows personalized learning that is not hindered by temporary or environmental limitations (H Crompton 2013; Baran 2019; Berge and Muilenburg; Mackay, Anderson, and Harding 2017). The evaluation of the effectiveness of digital teaching with information and communication technologies (ICT) and the evaluation of the improvements that suppose to the education are the essential points to determine the degree of success or failure of the digital teaching (Deng et al. 2018; Havens, Linn, and Boyle 2016). Numerous studies indicate the need to use evaluation for pedagogical purposes (Chen and Cheng 2008; Wissiak Grm and Savec 2014). This perspective emphasizes the "evaluation of learning" and especially the "evaluation for learning" that emphasizes the formative function of evaluation and the importance of providing information to students about their own learning process and possible ways to improve it. Evaluation is sometimes understood as an element that forms a point of union between the teaching processes in the classroom and the processes of construction of knowledge that the student performs, and that must be coherent with the rest of the students. Elements that make up the teaching and learning process (von Glasersfeld 1998).

ICTs are currently being used, rather for training purposes and support to teacher tutoring to student learning (Anderson and Enge 2012; Cox et al. 2016). On the other hand, the realization of evaluation activities with high levels of transparency enables the teacher to better monitor and regulate more interactive (process) and personalized to the student, while in situations of evaluation with low levels of transparency is often observed the absence of process supports and personalized by the teacher through ICTs (Lafuente Martínez et al. 2010).

This study aimed to implement in university students the use of conduct real-time theoretical questionnaire in class attendance using mobile devices with real-time resolution using online platforms with a later critical analysis of the results to promoting the use of new online technologies that allow adapting new changes and improve the learning and evaluation process. 


\section{METHODS}

\subsection{PARTICIPANTS}

A total of 300 university students belonging to a Medicine degree were analyzed from 2014 to 2018. The mean age of university students was $21 \pm 1.2$ years (mean \pm SD), and $37.1 \%$ corresponds to men, while $57.3 \%$ corresponds to women.

\subsection{COMPLIANCE WITH ETHICAL STANDARDS}

All students have participated in this study voluntarily. Written informed consent was obtained from all students. The institutional ethics committee approved this study in accordance with the Declaration of Helsinki and its later amendments or comparable ethical standards.

\subsection{DIGITAL TEACHING TOOLS}

In this study, a real-time questionnaire was conducted in the classroom using an online platform ("Live Interactive Audience Participation | Poll Everywhere" 2019). The students responded individually to each of the questionnaire questions using the Twitter application previously downloaded on their mobile devices with an internet connection. The students' different answers to the questionnaire's questions are visualized in real-time in the teaching classroom. This online platform allows to post the answers of each student anonymously or in a personalized way in the form of graphs in real-time.

\subsection{EVALUATION OF THE USE OF DIGITAL TECHNOLOGIES}

A survey of 13 questions was developed to know the students' opinions regarding using this digital technology in the classroom (Table 1). The student's evaluation by the initiative in the use of digital technologies in the classroom by the teachers and the overall satisfaction degree of the students was assessed employing questions 12 and 13 of the questionnaire. To assess questions 1 to 12, a dichotomous response model was used (Yes / No), and for questions 12 and 13, the Likert scale from 1 to 5 was used, which ranged between "not at all satisfied" or "totally satisfied ". In this study, two groups according to the degree of satisfaction, delighted (values 1, 2, and 3) and little satisfied (values 4 and 5), was established.

Table 1. Evaluation of the use of digital technologies in the classroom.

1. Did you know this evaluation system before? Yes/No

2. Has your attention increased on the material dealt with in class? Yes/No

3. Has the use of this online digital technology been useful in class? Yes/No

4. Did knowing about the results of the evaluations in real time increase your interest Yes/No in the subject?

5. Do you think it would be interesting to do tutoring classes, exams (review) using Yes/No 
questionnaires in real time in class?

6. Did you have a Twitter account before doing this practice? Yes/No

7. Have you found it uncomfortable using Twitter to have to do your evaluation? Yes/No

8. In the case of your degree studies, do you think it is important to use ICTs and Yes/No

Social Networks?

9. Do you think you have enough knowledge about ICT? Yes/No

10. Do you think that the use of ICTs by the teacher should be increased during the Yes/No lectures?

11. Have you managed to increase your interest and motivation for the subject? Yes/No

12. How would you rate the initiative taken by the teacher? $\quad 12345$

13. How would you rate this activity as a whole?

1223345

$1=$ Nothing, 2 = Little, 3 = Fair, 4 = Fairly, 5 = Strongly agree.

\subsection{STATISTICAL ANALYSIS}

Sociodemographic data and results of surveys were collected in a database (Microsoft Access 11.0; Microsoft Corporation, Seattle, WA), and statistical analysis was performed using the SPSS 19.0 software (SPSS Inc., Chicago IL, USA). Categorical data were compared using the chi-square test or Fisher's Exact test. A level of $\mathrm{P}<0.05$ was accepted as statistically significant. Odds ratios (OR) and their $95 \%$ confidence intervals $(\mathrm{CI})$ were calculated to estimate relative risk.

\section{RESULTS}

\subsection{ANALYSIS OF PREVIOUS KNOWLEDGE AND OPINION OF STUDENTS WITH THE ONLINE} EVALUATION SYSTEM

Our results showed that $94.4 \%$ of the students did not know these digital evaluation tools applied to the university teaching classroom. Its use increased the attention of the students by the subject taught (73.0\%). It should be noted that $86.5 \%$ of students considered and very useful the use of this teaching resource to increase the interest of students for the subject taught $(75.3 \%)$. It should be noted that he did not observe any statistically significant difference between men and women.

\subsection{ANALYSIS OF THE DEGREE OF STUDENT SATISFACTION ON DIGITAL EVALUATION WITH MOBILE DEVICES AND ONLINE PLATFORMS}

The students' overall satisfaction analysis showed delighted $(69.7 \%)$ for the use of new digital resources in their university education while only $30.3 \%$ felt little satisfied. Then, opinions were analyzed in both groups of students according to their level of satisfaction. It was observed in the group of students with a high degree of satisfaction a high frequency of attention on teaching contents $(85.5 \%)$ through the use of this digital evaluation tool, while $44.4 \%$ was observed in less satisfied students $(\mathrm{P}<0.0001)$ (Figure 1a). 
Figure $1 \mathrm{~b}$ shows that $96.8 \%$ of the students very satisfied and $63 \%$ of little satisfied. It was desirable to use these teaching resources in class $(\mathrm{P}<0.001)$. On the other hand, the analysis of the interest in the teaching subject evaluated through the use of real-time assessments allowed to detect an increase in interest in both groups of students (83.9\% and 55.6\%, respectively), although $44.4 \%$ of little satisfied students did not manage to increase their interest in the subject $(\mathrm{P}=0.007$, Figure 1c).

The opinion analysis on mobile applications and online platforms in tutoring classes or review exams using real-time questionnaires in class showed a high degree of acceptance $(77.4 \%)$ in the group of delighted students and only $37 \%$ in the group of students not very satisfied with the experience (P $<0.001$, Figure 2a). Most satisfied and unsatisfied students previously had an account on the digital platform Twitter (83.9\% and 55.6\%, respectively, Figure $2 \mathrm{~b}$ ). Figure $2 \mathrm{c}$ shows that $79 \%$ of satisfied students found it comfortable to use Twitter to answer online the evaluation questions, and similar results were found in a little satisfied group $(66.7 \%, \mathrm{P}<0.001)$.

Regarding the rest of the issues raised in the questionnaire, note that a high percentage of all students $(84.3 \%)$ consider using ICTs and new social networks important in their university education since only $43.8 \%$ of students declare to have enough knowledge about ICTs. On the other hand, students consider that new technologies should be increased (65.2\%) in their university studies in experimental sciences since they consider it essential to complete their academic training. Besides, this new teaching experience allowed to enhance the interest and motivation for the subject's contents in $75.3 \%$ of the students surveyed. Finally, most students (91.9\%) positively valued the teacher's initiative when incorporating these new teaching resources.

\section{DISCUSSION}

This study implemented in university students the use of conduct real-time theoretical questionnaire in class attendance using mobile devices with real-time resolution using online platforms projected in the classroom. These results promote new online technologies that allow adapting to new changes and improve the evaluation and learning process. For all these reasons, in this study, we have evaluated the opinion of the students with the use of the digital evaluation tool Poll-everywhere ("Live Interactive Audience Participation | Poll Everywhere" 2019) using a mobile device to promote selflearning, motivation, and interest in the subject, as well as the acquisition by of the student's knowledge and use of new ICT technologies in order to facilitate the teaching-learning process and evaluation of the contents.

The major reviews of mobile learning in education include a critical analysis of mobile learning projects are focused on six criteria: context, control, tools, communication, subject, and objective 
(Frohberg, Göth, and Schwabe 2009). Researchers have studied mobile learning in science education, but no one is using this resource to assess student learning, so that our study is the first one that uses mobile for that purpose. Previously, some studies promoted authentic practices in the science classroom using different technologies (Reiser 2006). With the implementation of these new tools in the teaching classroom, the results have also been evaluated affective and cognitive outcomes in all different subject areas of science (Swan and O'Donnell 2009; S. W. Lee et al. 2011b). Our results show a high degree of satisfaction in incorporating these new ways of evaluation and student learning in the molecular toxicology classroom. The students rated satisfactorily that teachers adapt their learning to a social reality where mobile devices are present.

However, the main contributions that emerged were simulations and visualizations, the generation of multimedia material, and integrated systems of complex learning (Swan and O'Donnell 2009; Rotbain, Marbach-Ad, and Stavy 2008; Thompson et al. 2010; Swan and O'Donnell 2009; Spiegel et al. 2008). Nowadays, the Massive Open Online Courses (MOOCs) ' educational phenomenon is emerging with great force (Christensen et al., 2013). These online courses provide students with opportunities to participate in learning the knowledge provided by many universities to expand their existing knowledge base or access courses that are not available at their home institution (Kaplan and Haenlein 2016).

The use of mobile learning in education is growing exponentially (Helen Crompton et al. 2016) and designing new mobile resources in science education is essential to understand better the interactions between mobile technologies and science education (Ally and Prieto-Blázquez 2014). Our result showed a great acceptance on the part of the students who express their opinion that their use should be extended for some tutorial sessions and even in review exams. Our results confirmed that when the student stops being a passive agent, receives information, and becomes an active agent in which the teacher acts as a coacher in the education of the student and is provided with the appropriate means, acquiring a leading role in their learning process, improves the motivation of students towards the activity in the classroom (Chin and Chia 2004; Cushion, Armour, and Jones 2003). It should be noted that interest and motivation for the evaluated teaching contents were enhanced in most of the students. Also, the evaluation system using Poll-everywhere implements a teaching methodology that promotes students' autonomous work, which results in a globally effective learning development (Drennan, Kennedy, and Pisarski 2005).

In this context, the association of diverse resources in class offers teachers the opportunity to follow up accurately the learning process of students and obtain evidence of the results achieved and the degree to which they have developed the competencies, being able to use them to support adequately to the students in their learning processes. Therefore, monitoring, tutoring, and the teacher's support for 
online students' work is undoubtedly one of the fundamental elements for the success of teaching and learning processes.

In conclusion, the use of the digital evaluation tool through online platforms and the use of mobiles in the classroom is an appropriate and useful didactic tool to teach and evaluate students, encouraging the students' motivation and interest in the subject promoting more active student participation.

\section{DISCLOSURE STATEMENT}

The author reported no potential conflict of interest.

\section{Figure legend}

Figure 1. Analysis of the students' results according to their degree of satisfaction to questions 2,3 , and 4 of the questionnaire.

\section{Figure 1}

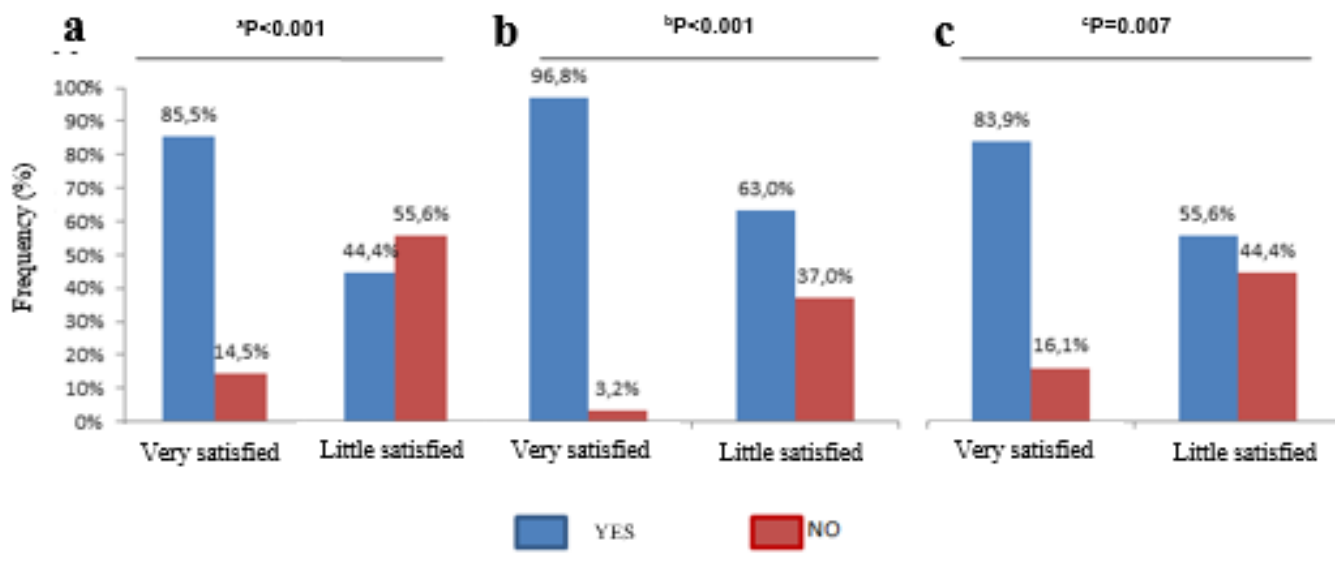

a) Has your attention increased on the material dealt with in class? b) Has the use of this online digital technology been useful in class? c) Did know about the evaluations' results in real-time increase your interest in the subject? aOR=7.631; 95\%CI: 2.609-20.765; bOR=17.647; 95\%CI: 3.524-88.361; cOR=4.160; 95\%CI: $1.505-11.502$ 
Figure 2. Analysis of the students' results according to their degree of satisfaction to questions 5, 6, and 7 of the questionnaire.

Figure 2

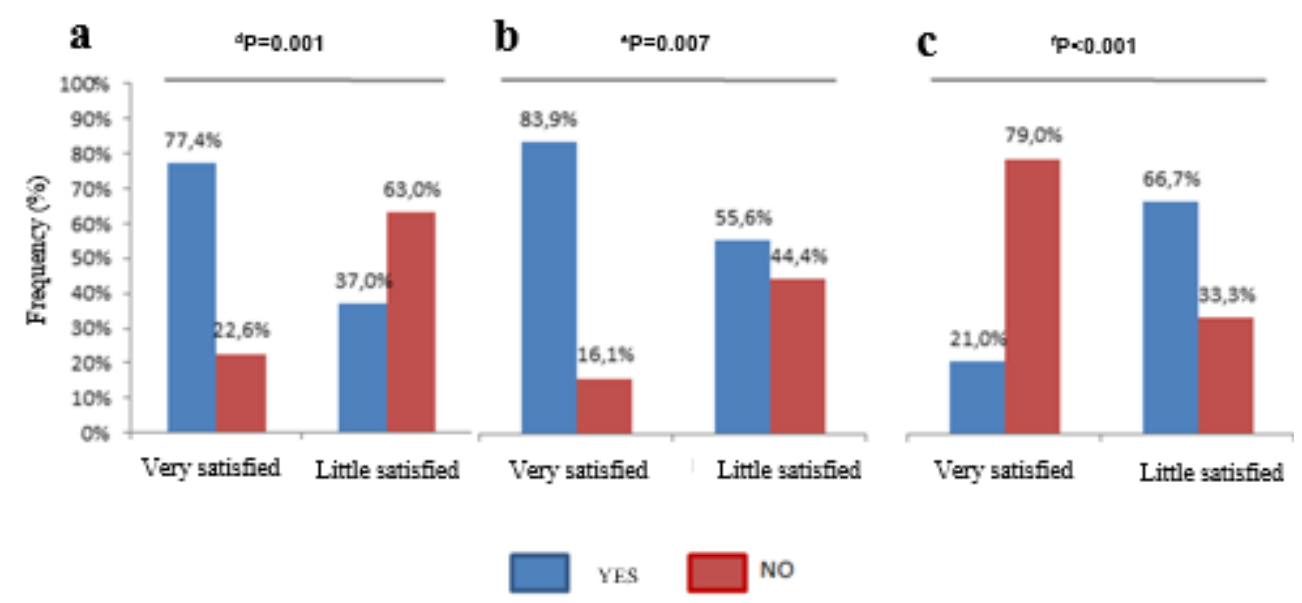

a) Do you think it would be interesting to do tutoring classes, exams (review) using questionnaires in real-time in class? b) Did you have a Twitter account before doing this practice? c) Have you found it uncomfortable using Twitter to have to do your evaluation? $\mathrm{dOR}=5.829 ; 95 \% \mathrm{CI}: 2.183-15.563$; eOR=4.160; 95\%CI: $1.505-11.502$;OR=0.133; $95 \% \mathrm{CI}$ : $0.048-0.363$ 


\section{REFERENCES}

Ally, Mohamed, and Josep Prieto-Blázquez. 2014. "Quin És El Futur de l'aprenentatge Mòbil En l'educació?" RUSC. Revista de Universidad y Sociedad Del Conocimiento 11 (1). Springer International Publishing: 142. doi:10.7238/rusc.v11i1.2033.

Anderson, Lori S., and Karmin J. Enge. 2012. "Education and Information for Practicing School Nurses." The Journal of School Nursing 28 (5): 358-369. doi:10.1177/1059840512443261.

Baran, Evrim. 2019. "A Review of Research on Mobile Learning in Teacher Education." Journal of Educational Technology \& Society. International Forum of Educational Technology \& Society. Accessed April 17. doi:10.2307/jeductechsoci.17.4.17.

Berge, Zane L., and Lin Y. Muilenburg. Handbook of Mobile Learning.

Chen, Chi-Fen Emily, and Wei-Yuan Eugene Cheng. 2008. "Beyond the design of automated writing evaluation: pedagogical practices and perceived learning effectiveness in efl writing classes" 12 (2): 94 112. http://llt.msu.edu/vol12num2/chencheng/.

Chin, Christine, and Li-Gek Chia. 2004. "Implementing Project Work in Biology through Problem-Based Learning." Journal of Biological Education 38 (2). Taylor \& Francis Group : 69-75. doi:10.1080/00219266.2004.9655904.

Christensen, Gayle, Andrew Steinmetz, Brandon Alcorn, Amy Bennett, Deirdre Woods, and Ezekiel J Emanuel. 2013. "The MOOC Phenomenon: Who Takes Massive Open Online Courses and Why?" SSRN Electronic Journal, November. doi:10.2139/ssrn.2350964.

Cox, S., D. Pollock, J. Rountree, and C. M. Murray. 2016. "Use of Information and Communication Technology amongst New Zealand Dental Students." European Journal of Dental Education 20 (3): 135141. doi:10.1111/eje.12151.

Crompton, H. 2013. "A Historical Overview of Mobile Learning: Toward Learner-Centered Education. In ZL Berge \&amp; LY Muilenburg (Eds.), Handbook of Mobile Learning (Pp. 3-14)." https://scholar.google.es/scholar?hl=es\&as_sdt=0\%2C5\&q=A+historical+overview+of+mobile+learnin $\mathrm{g} \% 3 \mathrm{~A}+$ toward+learner-centered+education.\&btnG=.

Crompton, Helen, Diane Burke, Kristen H. Gregory, and Catharina Gräbe. 2016. "The Use of Mobile Learning in Science: A Systematic Review." Journal of Science Education and Technology 25 (2). Springer Netherlands: 149-160. doi:10.1007/s10956-015-9597-x.

Cushion, Christopher J., Kathy M. Armour, and Robyn L. Jones. 2003. "Coach Education and Continuing Professional Development: Experience and Learning to Coach.” Quest 55 (3). Taylor \& Francis Group : 215-230. doi:10.1080/00336297.2003.10491800.

Deng, Xiaohua, Guowei Zhou, Bing Xiao, Zirui Zhao, Yicheng He, and Chujun Chen. 2018. "Effectiveness Evaluation of Digital Virtual Simulation Application in Teaching of Gross Anatomy." Annals of Anatomy - Anatomischer Anzeiger 218 (July): 276-282. doi:10.1016/j.aanat.2018.02.014.

Frohberg, D., C. Göth, and G. Schwabe. 2009. "Mobile Learning Projects - a Critical Analysis of the State of the Art." Journal of Computer Assisted Learning 25 (4). John Wiley \& Sons, Ltd (10.1111): 307-331. 
doi:10.1111/j.1365-2729.2009.00315.x.

Havens, Laura, Aileen Linn, and James Boyle. 2016. "Teaching Digital Professionalism: A Role for Problem-Based Learning?” The Clinical Teacher 13 (6): 463-463. doi:10.1111/tct.12559.

1220

Kaplan, Andreas M., and Michael Haenlein. 2016. "Higher Education and the Digital Revolution: About MOOCs, SPOCs, Social Media, and the Cookie Monster." Business Horizons 59 (4). Elsevier: 441-450. doi:10.1016/J.BUSHOR.2016.03.008.

Lafuente Martínez, Marc., Ibis Marlene Álvarez Valdivia, César Coll, and Universitat de Barcelona. Departament de Psicologia Evolutiva i de l'Educació. 2010. Evaluación de Los Aprendizajes Mediante Herramientas TIC Transparencia de Las Prácticas de Evaluación y Dispositivos de Ayuda Pedagógica. TDX (Tesis Doctorals En Xarxa). Universitat de Barcelona. https://www.tesisenred.net/handle/10803/2657.

Lee, Silvia Wen-Yu, and Chin-Chung Tsai. 2013. "Technology-Supported Learning in Secondary and Undergraduate Biological Education: Observations from Literature Review." Journal of Science Education and Technology 22 (2). Springer Netherlands: 226-233. doi:10.1007/s10956-012-9388-6.

Lee, Silvia Wen-Yu, Chin-Chung Tsai, Ying-Tien Wu, Meng-Jung Tsai, Tzu-Chien Liu, Fu-Kwun Hwang, Chih-Hung Lai, Jyh-Chong Liang, Huang-Ching Wu, and Chun-Yen Chang. 2011a. "Internetbased Science Learning: A Review of Journal Publications." International Journal of Science Education 33 (14). Routledge : 1893-1925. doi:10.1080/09500693.2010.536998.

Lee, Silvia Wen-Yu, Chin-Chung Tsai, Ying-Tien Wu, Meng-Jung Tsai, Tzu-Chien Liu, Fu-Kwun Hwang, Chih-Hung Lai, Jyh-Chong Liang, Huang-Ching Wu, and Chun-Yen Chang. 2011b. "Internetbased Science Learning: A Review of Journal Publications." International Journal of Science Education 33 (14). Routledge : 1893-1925. doi:10.1080/09500693.2010.536998.

Linn, Marcia. 2003. "Technology and Science Education: Starting Points, Research Programs, and Trends." International Journal of Science Education 25 (6). Taylor \& Francis Group : 727-758. doi:10.1080/09500690305017.

"Live Interactive Audience Participation | Poll Everywhere." 2019. Accessed April 10. https://www.polleverywhere.com/.

Mackay, B.J., J. Anderson, and T. Harding. 2017. "Mobile Technology in Clinical Teaching." Nurse Education in Practice 22 (January): 1-6. doi:10.1016/j.nepr.2016.11.001.

Reiser, Brian. 2006. "Making Authentic Practices Accessible to Learners: Design Challenges and Strategies." Cambridge University Press. https://www.scholars.northwestern.edu/en/publications/making-authentic-practices-accessible-tolearners-design-challeng.

Rotbain, Yosi, Gili Marbach-Ad, and Ruth Stavy. 2008. "Using a Computer Animation to Teach High School Molecular Biology.” Journal of Science Education and Technology 17 (1). Springer Netherlands: 49-58. doi:10.1007/s10956-007-9080-4.

Soderberg, Patti, and Frank Price. 2003. "An Examination of Problem-Based Teaching and Learning in Population Genetics and Evolution Using EVOLVE, a Computer Simulation." International Journal of 
Science Education 25 (1). Taylor \& Francis Group : 35-55. doi:10.1080/09500690110095285.

Spiegel, Carolina N., Gutemberg G. Alves, Tâ da S. Cardona, Leandra M. C. Melim, Mauricio R. M. Luz, Tania C. Araújo-Jorge, and Andrea Henriques-Pons. 2008. "Discovering the Cell: An Educational Game about Cell and Molecular Biology." Journal of Biological Education 43 (1). Taylor \& Francis Group : 27-36. doi:10.1080/00219266.2008.9656146.

Swan, Aubrie E., and Angela M. O'Donnell. 2009. "The Contribution of a Virtual Biology Laboratory to College Students' Learning." Innovations in Education and Teaching International 46 (4). Routledge : 405-419. doi:10.1080/14703290903301735.

Thompson, Katerina V., Kären C. Nelson, Gili Marbach-Ad, Michael Keller, and William F. Fagan. 2010. "Online Interactive Teaching Modules Enhance Quantitative Proficiency of Introductory Biology Students." Edited by John Jungck. CBE-Life Sciences Education 9 (3): 277-283. doi:10.1187/cbe.1003-0028.

von Glasersfeld, Ernst. 1998. "Cognition, Construction of Knowledge, and Teaching." In Constructivism in Science Education, 11-30. Dordrecht: Springer Netherlands. doi:10.1007/978-94-011-5032-3_2.

Wissiak Grm, Katarina S, and Vesna Ferk Savec. 2014. "The Self-Evaluation of Slovenian Prospective Chemistry Teachers' Progress during Their Practical Pedagogical Training in Primary Schools." Acta Chimica Slovenica 61 (4): 729-739. http://www.ncbi.nlm.nih.gov/pubmed/25551712. 